\title{
CLARIN-IT and the Definition of a Digital Critical Edition for Ancient Greek Poetry
}

\author{
A New Project for Ancient Fragmentary Texts with a Complex Tradition
}

\author{
Anika Nicolosi \\ Department DUSIC \\ University of Parma, Italy \\ anika.nicolosicunipr.it
}

\author{
Monica Monachini \\ ILC - CNR \\ Pisa, Italy \\ monica.monachini@ilc.cnr.it
}

\author{
Beatrice Nava \\ Alma Mater Studiorum \\ University of Bologna, Italy \\ beatrice.nava2eunibo.it
}

\begin{abstract}
Ancient Greek studies, and Classics in general, is a perfect field of investigation in Digital Humanities. Indeed, DH approaches could become a means of building models for complex realities, analyzing them with computational methods and sharing the results with a broader public. Ancient texts have a complex tradition, which includes many witnesses (texts that handed down other texts) and different typologies of supports (papyri, manuscripts, and epigraphs). These texts are the basis of all European Literatures and it is crucial to spread their knowledge, in a reliable and easy way. Our project on ancient Greek fragmentary poetry (DEA - Digital Edition of Archilochus: New models and tools for authoring, editing and indexing an ancient Greek fragmentary author), growing out of the existing experience, tries to define a TEI-based digital critical edition combined with NLP techniques and semantic web technologies. Our goal is to provide a complete and reliable tool for scholars, suitable for critical studies in Classics, and a user-friendly environment also for non-specialist users. The project represents one of the attempts within the context of CLARIN-IT to contribute to the wider impact of CLARIN on the specific Italian community interested in Digital Classics. It is intended to improve services in fostering new knowledge in SSH digital research and sustaining the existing one.
\end{abstract}

\section{State of the art: Classical Studies in the Digital Era}

The era of data outbreak and digital consumption has significantly changed and keeps changing it with increased emphasis on interdisciplinary studies and new technologies. In this context, even Classical Philology needs to provide new methods and concepts capable of both seizing opportunities and addressing the challenges that technologies can offer to the discipline, in particular to the development of a scholarly, born-digital, edition of the ancient texts. Conversely, in the field of language technologies, the needs for a wider audience, with diverse profiles, opens up new challenges: easily usable tools, adaptable to different types of content, become crucial. Texts in the humanities' fields can often be heterogeneous (by genre, by era, by type) and the quality of resources, in particular the quality of digital editions of texts, is receiving increasing attention.

Classics, in general, is a perfect field to demonstrate how Digital Humanities could become the humanist way of building complex models of complex realities, analyzing them with computational methods and communicating the results to a broader public. Digital Classics have undergone a great development, starting from the last ten years of the $20^{\text {th }}$ century, and today we have many sources available and refined tools, ${ }^{1}$ e.g. the main tools in the field as the Thesaurus Linguae Graecae (TLG) ${ }^{2}$ and the

This work is licenced under a Creative Commons Attribution 4.0 International Licence. Licence details: http:// creativecommons.org/licenses/by/4.0/

\footnotetext{
${ }^{1}$ For the state of the art of digital philology with a focus on Ancient Greek and Latin, see Berti (2019).

${ }^{2}$ It offers texts and grammatical analysis of the texts, linking to LSJ and other sources (http://stephanus.tlg.uci.edu/)). 
Perseus Digital Library (PDL). ${ }^{3}$ There are also other very important projects, e.g. Digital Corpus of Literary Papyri (DCLP) ${ }^{4}$ and Trismegistos ${ }^{5}$ in general, Centre de Documentation de Papyrologie Littéraire $\left(\mathrm{MP}^{3}-\mathrm{CeDoPaL}\right),{ }^{6}$ The Leipzig Fragmentary Texts Open Series (LOFT) ${ }^{7}$ Musisquedeoque, ${ }^{8}$ Pinakes, ${ }^{9}$ and bibliographical tools as Annè Philologique $(\mathrm{APh}) .{ }^{10}$ Quite often these initiatives do not interact with each other, and they are only known by specialist users. At this stage, they are very important tools, but they cannot (or do not want to) replace paper editions.

We also have to consider that the treatment of literary texts currently does not correspond to scholars' expectations. These texts have a complex tradition, which includes many witnesses (texts that handed down other texts) and different typologies of supports (papyri, manuscripts and also inscriptions). To accomplish a complete understanding of certain topic, it is not enough to provide a traditional paper text; much more information is needed that scholars usually obtain by comparing several paper editions, lexica and/or more digital tools and imagines. We have now the opportunity to change this scenario, since digital technology allows us to manage much more data and adopt new approaches to a traditional discipline. Fostering the development of new learning habits, we can improve more modern research methodologies and new practices in didactics (always based on the good practices inherited from the previous tradition).

\section{Ancient Greek Poetry and Digital Edition: texts with a complex tradition}

DH may help to realize something new in the field. It is not enough today to only describe materials, and/or give information, and/or make available texts and/or analyze them, etc. It is necessary to integrate all these functions in a unique workbench where the researcher can find all (s)he needs. And to achieve this it is essential to focus on a specific case study. We think that the ancient Greek literature can be the right test, thanks to its potentialities and peculiarities.

Thanks to modern science we can preserve and hand down ancient Greek texts to next generations (not only among specialists in the field), exactly what ancient scholars did many centuries ago at the Alexandrian Library (3rd c. BCE). Fragmentary ancient Greek poetry is very different from other literary texts. In fact, its tradition is more complex since it has different kinds of sources (manuscripts, papyrus, epigraphs) with variants and lacunae. It is not enough to provide a single text randomly chosen; it is necessary to carry out a complete revision of the texts, according to their updated critical edition, and take into account all the textual proposals made by scholars. In this way, studying previous editions and the secondary literature, it is possible to enrich the new edition with new hypotheses. ${ }^{11}$

As noted by Pierazzo (2014), scholars agree that a digital edition, in addition to allowing direct or mediated access to a collection of information larger than the one currently available on paper, must be designed in such a way that ensures the greater freedom allowed by the tablet or the personal computer support. This digital versatility lacks in the paper edition. The digital medium, as we know, allows us to manage much more data than we can do in a paper edition, in which the apparatus must often be proportionate to the size of the page and therefore often provides only the main proposals. We can easily manage and store in a single place all the hypotheses of previous editors and the additional useful information linked to the edition; therefore, we can facilitate a new philological approach offering all the

\footnotetext{
${ }^{3}$ It offers texts, translations and grammatical analysis of the texts, linking to LSJ. Unfortunately, it offers miscellaneous text and presents old (out of copy-right) editions. For example, Archilochus, as a single author is not available; there are only texts and translations, with notes, of all iambographers, ed. by Edmonds in 1931 (http://www.perseus.tufts.edu/hopper/).

${ }^{4}$ The project, by Heidelberg and New York University, is an enlargement for literary papyrus' texts of Papyri.info (editing tool for documentaries papyrus' texts). DLCP and Papyri.info integrate tools for philological research, aggregating fundamental international resources for the study of antiquity; they provide resources to easily edit papyrus' texts, using Leiden+ mark-up language from EpiDOC, TEI/XML based, specific to ancient texts (http://litpap.info/).

${ }^{5}$ As, for example, Leuven Database of Ancient Books (LDAB) https://www.trismegistos.org/ldab/graphs help.php

${ }^{6}$ http://web.philo.ulg.ac.be/cedopal/fr/

${ }^{7}$ For literary fragmentary ancient prose texts (http://www.dh.uni-leipzig.de/wo/lofts/) developed as the digital recognition of a traditional book about Istro's prose fragments ( ${ }^{\text {rd }}$ c. BCE), linked to PDL, see Almas and Berti (2013).

${ }^{8} \mathrm{http}: / /$ mizar.unive.it/mqdq/public/ricerca/avanzata

9 https://pinakes.irht.cnrs.fr/

${ }^{10} \mathrm{http} / / / \mathrm{www}$. brepols.net/Pages/BrowseBySeries.aspx?TreeSeries=APH-O

${ }_{11}$ See Nicolosi (2015).
} 
interpretations of previous editors through a single resource, with the addition of new scholars' hypotheses.

At the same time, applying Natural Language Processing (NLP) techniques to a collection of fragmented texts can be particularly challenging because of the multiple options for text reconstruction. Automatic linguistic analyses of the whole corpus of fragments can indeed not only support new readings and interpretations but also lead us to a greater certainty as regards text corrections, integrations and authorship attribution. Moreover, by enriching the fragments with a set of specific lexica in appropriate format we facilitate data searchability and interoperability.

\subsection{DEA Project: A new Digital and Critical Edition}

DEA, which stands for Digital Edition of Archilochus: New models and tools for authoring, editing and indexing an ancient Greek fragmentary author, is a project lead by Anika Nicolosi (University of Parma), principal investigator, in collaboration with ILC-CNR of Pisa and CLARIN-IT. The project brings different expertise and skilful researchers together, combining philological and computational linguistic skills, ${ }^{12}$ it takes advantage from philological studies about ancient Greek literature and from recent methodological approaches to language resources developments. Our project grows out of existing experiences and tries to define a new and complete digital edition of Archilochus' fragments, which includes the use of Linked Open Data (LOD). ${ }^{13}$

We have around 300 fragmentary poems by Archilochus, who lived in the $7^{\text {th }}$ century BCE and who was closely related to Homer. This poet is crucial for Western literary tradition because Greek and Latin authors often mention him, ${ }^{14}$ and many of his themes and motives (war, myth, love) are then echoed in modern western literature. Some fragments have only recently been published, however, what is currently lacking is a complete on-line critical edition of his works. ${ }^{15}$

The project plans to develop an innovative digital portal, to become a reference for the studies on the Ancient Greek author(s), DEA will not develop a tool that replicates or integrates the traditional ones; the new platform aims to become an essential resource for the study of an ancient author, scientifically updated and reliable. The main objective of the project is, hence, to provide scientifically reliable texts, with critical apparatuses, and translations, and to make available an online and easily accessible augmented corpus of ancient Greek fragmentary literature. For this reason, it is important to find an easy and effective way of managing all these data, also according to the dictates and the needs of the philological tradition.

The DEA project also aims at defining a methodology for a digital critical edition. Moreover, one of the DEA's main goal is to develop resources, materials and tools in order to improve research in Greek Classical philology, integrating the digital resources already available with new ones. The DEA project involves the digitization, with critical and philological control, of the whole corpus of Archilochus' fragments, supplemented with a complete apparatus. The result will be a new typology of a complete, augmented, scholarly, born-digital, edition (annotated and interoperable according to current standards, enriched with information from lexical and geographic knowledge) with particular attention to users' needs and requirements, and to usability and portability. DEA is well placed to become a model for the digitalization of authors with a complex text tradition, in particular, fragmentary ancient authors.

The result will be an innovative tool that will become fundamental to share research and data, by combining the accuracy of traditional philology with new and more intuitive use and access. The objective is to manage the critical information and support:

\footnotetext{
${ }^{12}$ It arises from the experience in the field of Prof. Nicolosi (University of Parma) who has several international studies in the field (journals and Meetings' Proceedings), and 3 monographs about Archilochus (2007, 2013, 2017), and the resources and tools developed by the Pisa group and hosted by the Italian CLARIN-IT national data centre.

${ }^{13}$ See Monachini, Khan, Frontini and Nicolosi (2018) and Brando, Frontini and Ganascia (2016).

${ }^{14}$ We can mention, among others: later Greek authors, as Pindar, Critias, Aristophanes, Old Comedy in general, Herodotus, Plato, Aristoteles, New comedy, Callimachus, Theocritus, Apollonius Rhodes, Epigrammatic poets (as Dioscorides, Meleager, etc.); among the Roman poets, authors as Lucillius, Horace, Catullus, Quintilian; Greek authors of Imperial period, as Ps.Longinus, Emperor Hadrian, Dion of Prusa, Plutarch, Sextus Empiricus, Emperor Julian, Patristic authors (as Clement of Alexandria, Origen and Synesius); Menander Rhetor.

${ }^{15}$ The work starts from Nicolosi (2013) and Nicolosi (2017).
} 
- new readings and interpretations;

- stronger certainty of corrections, integrations;

- authorship attribution;

- creation of a corpus of fragmentary ancient texts;

- searchable and interoperable data;

- enrichment of data with lexical datasets in LOD and other existing resources;

- a complete edition that is useful not only for scholars interested in Classical and Ancient Studies but also for non-specialists.

The online platform aims to become an interdisciplinary, multi-purpose research tool, enabling the final user to browse, explore and study digital editions by means of a user-friendly interface. Scholars and students will be able to easily access and search the complete corpus of the ancient author, accessing reliable critical and scientific information related to the field of study.

To reach these objectives and to set up the project correctly, we have tested the solutions to make all data searchable and easily interoperable. The first step is the TEI transcription and the annotation of the text. We have developed a case-study on a sample of TEI Archilochus' fragments with text, apparatus and witness, linguistic analysis, translations and commentary, with reference to Nicolosi (2013). This constitutes a pilot set of Archilochus' papyrus texts with metadata, bibliography, translation, and apparatus.

We are testing some functional solutions with the TEI encoding, both for managing the critical apparatus and witnesses and for representing textual phenomena of classical philology (lacunae, uncertain readings, omissions, corrections). The aim is to find a measured balance between the accuracy that philological study requires, and the synthesis provided by digital tools, with the purpose of making information accessible in a user-friendly, yet controlled and organized manner. It is necessary a more detailed annotation level that configures the text in its complexity and makes visible gaps, supplements, and doubtful readings. For this purpose we are using the TEI guidelines ${ }^{16}$ (mostly the tagset of the module 11: Representation of Primary Sources. See Figure 1). ${ }^{17}$

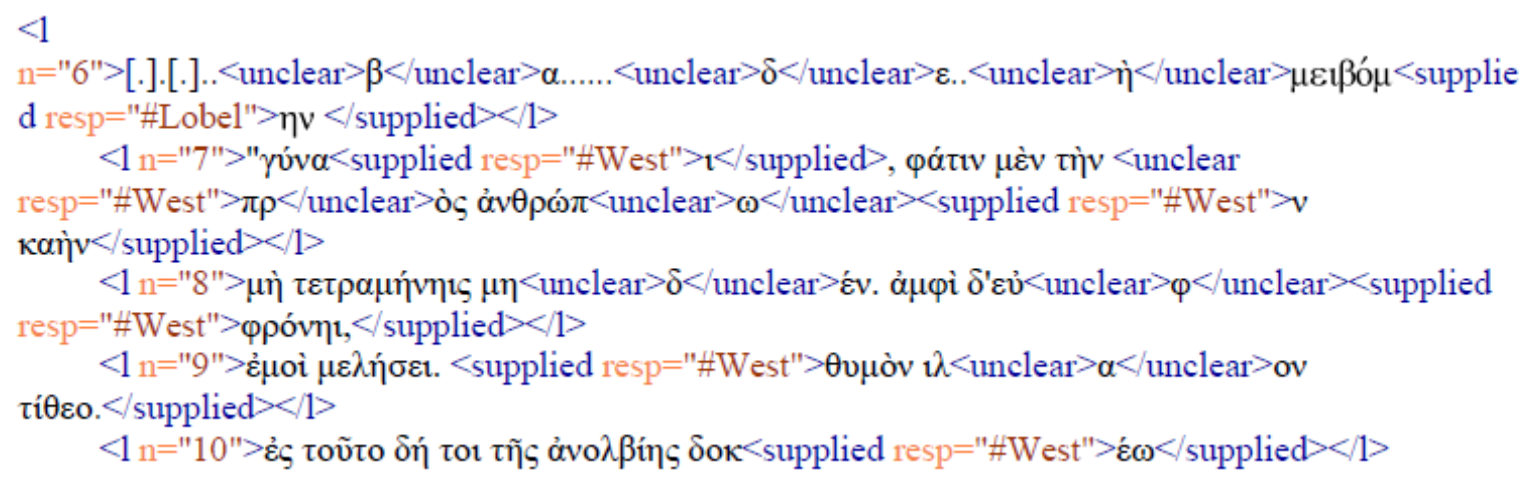

Figure 1

Starting from the module Critical Apparatus of the TEI guidelines, we are encoding three different annotation levels, divided along different typologies of witnesses and different text's references.

1. The tag < listWit> includes:

a) ancient witness, associated with an xml: id and some essential information $(<\mathrm{msDesc}>)$;

b) modern editions, each associated with an $\mathrm{xml}$ : id and the complete bibliographic reference $(<$ bibl $>)$.

\footnotetext{
16 The current version of the guidelines is the P5. See https://www.tei-c.org/release/doc/tei-p5-doc/en/html/index.html.

${ }^{17}$ The text's reference for these exempla is Archil. fr. $23 \mathrm{~W} .^{2}$, studied by Beatrice Nava during her BA level thesis in Classics, a.a. 2013/2014, Tutor Prof.ssa A. Nicolosi, at the University of Parma.
} 
2. The tag < listBibl $>$ includes bibliographic references, associated with an xml: id of:

a) secondary literature;

b) ancient texts (not indirect witnesses, but used for conjecture).

\begin{tabular}{|c|c|}
\hline TEIHEADER & \\
\hline Typology & Mark \\
\hline Title & 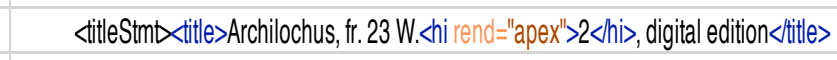 \\
\hline Author (and other responsabilities) & <espStmb \\
\hline & 〈resp>Encoding (or other responsabilities)<rresp> \\
\hline & $\langle$ persName xmlid="niziali nome puntate" $>$ Name and Sumame<persName> \\
\hline & $<$ respStmb <litteStmb \\
\hline Digital Edition & «publicationStmb \\
\hline & <publisher>D.E.A - Digital Edition of Archilochus' fragments</publisher> \\
\hline & $\langle p u b P l a c e>P a r m a<p u b P l a c e>$ \\
\hline & $<$ date $>2018<$ date $>$ \\
\hline & <availability> \\
\hline & $\langle p\rangle$ This fragment is avaliable only for demonstration purposes. (user license) $\langle p\rangle$ \\
\hline & বavaliability \\
\hline & $<$ spublicationStm〉 \\
\hline Source Description & $\langle$ sourceDesc $\rangle$ \\
\hline & $\langle b i b l>$ \\
\hline Title & 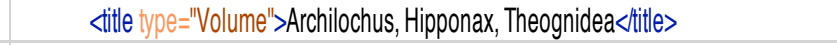 \\
\hline Author and Fragmet & <itte type="Part"Aarchilochus, fr. 23 W. Łi rend="apex">2</hix<title> \\
\hline Meter & 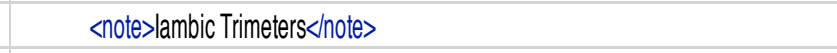 \\
\hline Ancient Author & <author xmlidid="Archilochus">Archilochus〈author \\
\hline
\end{tabular}

Figure 2

The coding of the apparatus is made with the parallel segmentation method. In the apparatus $(<\mathrm{app}>)$ we can differentiate between, for example:

a) Lesson of the reference text (e.g. Nicolosi), for example with the tag $<$ lem $>$ i $\lambda<$ unclear $>\alpha</$ unclear $>$ ov $</$ lem $>$

b) Reading proposed in a modern edition (related to listWit), for example $<$ rdg wit="\#Latte_1955" $>$ ' $\lambda \lambda<$ unclear $>\varepsilon</$ unclear $>$ ov $</$ rdg $>$

c) Reading from secondary literature (reference refers to listBibl), for example $<$ rdg wit="\#Bossi_1990" $>$ example $</$ rdg $>$

d) Hypothesis of a modern editor supported by an ancient text, indicated with @source; here the reference refers to listBibl, for example <rdg wit="\#Adrados_1990" source $=$ "\#Exemplum" $>$ example $</$ rdg $>$ 


\begin{tabular}{|c|c|}
\hline TEXT & \\
\hline Section & $<$ div type="tipo_di_sezione_es:titilo" cert="000" $>/$ dir $>$ \\
\hline Number of the verse & $\triangleleft x m:: 1 d=" 1.1 ">$ \\
\hline Gap (uncertain length) & <gap reason="lost" extent="unknown" unit="chars"l> \\
\hline Gap (certain length) & 〈gap reason="lost" quantity="00" unit="chars" cert="grado_di_certezza"l> \\
\hline Lines lost & <gap reason="lost" extent="unknown" unit="lines"|> \\
\hline Letters (illegible) & <gap reason="illegible" quantity="2" unit="chars"ا> \\
\hline Reading (unclear) & $<u n c l e a r>\mid \sigma</ u n c l e a r>$ \\
\hline Supplement (uncertain letters) & <supplied reason="illegible">K/supplied> \\
\hline Supplement (lost letters) & <supplied reason="lost"><</supplied> \\
\hline Text deleted (ancient witness) & $<$ del rend="erasure" >aß</del> \\
\hline Text deleted and illegible (ancient witness) & $\langle$ del rend="erasure" $><$ gap reason="lost" quantity="3" unit="character"| $|>\langle$ del $>$ \\
\hline Text added (ancient witness) & $<$ add place="000" >aß</add > \\
\hline Text deleted (modern editor) & $\langle$ surplus>aß $\gamma<$ ssurplus $>$ \\
\hline Text added (modern editor) & 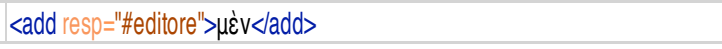 \\
\hline
\end{tabular}

Figure 3

To standardize the model, we created a TEIheader that contain a structured detailed description of the content of ancient texts (Figures 2 and 3). In this model, that can be applied to both manuscript texts and papyrus (or epigraphy) texts, the metadata include general information such as bibliographical sources, manuscript or papyrus (or epigraphy) description, available open data (as imagines); in the $<$ body $>$, we encode gaps, lacunae, different readings, corrections, symbols and then apparatuses with scholars' readings and hypotheses. The idea is to test, at this stage, the usability of what the TEI guidelines suggest. These guidelines proved to be suitable for our purposes, since they cover all our needs. Even if the coding is often time consuming, we think it would be important to keep using XML/TEI directly, without any TEI encoding tool. This allows us to have the control on the information we are encoding and, at the same time, to re-think our model, thus making it more and more accurate for our research goals. In this sense, we are not doing something new: we are not suggesting new TEI elements or new encoding models; we are simply facing some of the encoding problems as other projects. ${ }^{18}$

However, we are doing something that has never been done before. Indeed, by looking at the complete and up-to-date catalogue of digital edition compiled by Franzini ${ }^{19}$ we find that, out of a total amount of 309 editions, there are only 18 scholarly editions based on antique sources and using an XML/TEI transcription. Five of them are a reproduction of a printed edition, but none of them concerns ancient Greek poetry and provides a critical apparatus. Moreover, only 3 of these editions provide a full text transcription, but, again, without a clear critical apparatus. Another aspect of novelty is the use of standards and best practices from the Semantic Web which ensures interoperability with resources available as Linked Open Data (LOD). We are able to augment our digital edition by linking the information contained in the fragments to the structured knowledge available in language resources published as LOD, thus allowing much more complete analyses.

It is the case of e.g. the Lexicon LSJ-LOD which allows us to deepen the linguistic analysis, or the Pleiades Gazetteer of ancient places which allows the enrichment of our edition with geospatial references. We have already linked some of the geographical references contained in the fragments to the Pleiades and obtained a nice improved version of the text itself, thus exploiting the potential of resources made available to scholars.

The next step foresees to develop a treebank: Archilochus' fragments can be collected in a corpus of syntactically annotated fragments to be used, as a gold standard to train systems aimed at performing automatic syntactic analysis of ancient Greek fragmentary texts. The treebank will be provided with textual analysis coupled with translations to be used in a didactic context to foster studying, teaching, and learning of ancient Greek language and literature.

\footnotetext{
${ }^{18}$ For example, regarding the coding of primary sources transcriptions we are using the same XML/TEI model used by other editions based on text of different periods, e.g. Medieval Nordic Text Archive (Menota), Jane Austen's Fiction Manuscripts Digital Edition, the DCLP project, mentioned above etc.

${ }^{19}$ The catalogue is available online at https://dig-ed-cat.acdh.oeaw.ac.at.
} 
Finally, we can use the results obtained in this small but complex field of study to create a replicable model for other fields of literary studies. The investigation of technological aspects should hopefully act as an important test for future projects in the field of classical studies.

\subsection{CLARIN-IT and DEA project: data and metadata}

Research Infrastructures (RI) are a key element that can provide significant developments as they offer opportunities to store, develop and share data and tools; they are the perfect framework where to spread knowledge about good practices related to a discipline. CLARIN-ERIC (www.clarin.eu), the Common Language Resource Infrastructure for SSH, was born to promote the development of technological solutions aimed at making language resources available to scholars, researchers, students through a unified and standardized mode of access to data and computational tools. This involves making available digital repositories where data, tools and language services are catalogued, stored, retrieved and used in a simple and intuitive way by users. It represents the perfect solution to bring together producers and developers of language technology with its users.

The digitization of Archilochus' texts allows the creation of a philologically and critically controlled product and is aimed to develop crucial resources, materials, and tools for study and research in the field. The project represents one of the attempts within the context of CLARIN-IT ${ }^{20}$ to contribute to the wider impact of CLARIN on the specific Italian community interested in Digital Classics. It may help to develop services aimed to foster new knowledge in SSH digital research ${ }^{21}$ and to sustain the existing one. The case study dealt with in CLARIN is meant to offer the opportunity to develop a new type of approach to the study of Classics, opening new horizons for the storage, analysis and study of data of the discipline.

As Nava (2019) points out: "DEA can be regarded as a case study in the framework of CLARIN-IT and its interests and specialization towards the Digital Classics. The ILC4CLARIN repository (https://ilc4clarin.ilc.cnr.it/) offers the corpus, along with other existing digitized resources for Ancient Greek provided as. LOD. ${ }^{22}$ This allows us to enrich our corpus with LOD lexical datasets and to integrate our data with other existing resources, with the final aim of obtaining a complete edition that is useful not only for scholars interested in Classical and Ancient Studies but also for non-specialist users."

Moreover, as she said: "linguistic annotation allows the development of new teaching methods of Ancient Greek that are aimed at encouraging beginners and the creation of new resources to be integrated in frameworks, such as TüNDRA (https://weblicht.sfs.uni-tuebingen.de/Tundra/), specifically implemented for Classics. More generally, the annotations enable an interactive approach to texts that is more inviting and immediate for the students. [...] In our case, having a corpus of fragmentary texts allows us to develop linguistic services for teaching (e.g. Hyper-Text Archilochus)" ${ }^{23}$ To sum up, improving the currently existing tools for Ancient Greek with regards to their performance on fragmentary texts would offer very important upgrades for the study and teaching of Ancient Greek.

At this stage, we only tested some cases (encoding text and metadata) and we stored them in the CLARIN-IT repository. We profited from a Clarin Mobility Grant to advance our studies and our knowledge ${ }^{24}$ it was a clear example of how CLARIN can profitably contribute to training activities. ${ }^{25}$ In addition, we can consider that an experience like the Tour de CLARIN (in Italy from $1^{\text {st }}$ February to $31^{\text {th }}$ March 2019, see http://www.ilc.cnr.it/it/content/tour-de-clarin-it) can spread knowledge and can be fundamental for the dissemination of research projects.

\footnotetext{
${ }^{20}$ See Monachini and Frontini (2016).

${ }^{21}$ See Monachini et al. (2018).

${ }^{22}$ Version of the TEI-dict Perseus Liddell-Scott Jones Greek-English dictionary (http://lari-datasets.ilc.cnr.it/ml/).

${ }^{23}$ It is only a preliminary study to test a sample of a prototype that provides the learner with a set of resources and tools that ease a critical assessment of ancient texts (http://hdl.handle.net/20.500.11752/OPEN-83).

${ }^{24}$ See CLARIN blog (https://www.clarin.eu/blog/tei-and-ancient-greek-fragmentary-poetry).

${ }^{25}$ A seminar was given also in Parma (https://www.clarin.eu/blog/clarin-it-presents-their-roadshow-seminars).
} 


\section{Conclusions: addressing a specific research challenge}

The DEA project is currently under development and we hope that its implementation will foster the training of new professional figures specialized in a specific research field of the Digital Classics. The project is intended to deal with a well-defined number of fragments of a single author that will be investigated and made available in a complete and reliable way, but the final aim is to provide a replicable model for studies of wider interest related to Ancient Poetry, as Ancient Greek Song and/or Hellenistic Poetry.

DEA aims at bridging the digital gap between traditional studies and the growing world of data. It is focused on applying Digital Humanities methods - such as XML-TEI encoding or NLP technologies to poetry analysis, classification, and publication, in order to ensure accessibility, interoperability, sharing, enrichment. These objectives are ensured by using semantic web technologies to link and publish literary datasets in a structured way in the Linked Data cloud, thus ensuring the interaction between texts and terminologies, ontologies, lexicons available as LOD.

The final aim of the project is to make available and easily accessible - for scholars, students, and common people - scientifically reliable texts of the ancient literary, that is crucial for our Cultural Heritage. This allows the development of new tools in the form of a collaborative workbench for the creation of digital edition which goes beyond the limits of paper editions. Moreover, the creation of a corpus and a treebank can help to deepen the study of ancient Greek structures and may have strong impact on the study and learning of the ancient Greek and the ancient literature in general, thus allowing to develop a portfolio of competences for users at different stages of learning. From a long-term perspective, collecting trees in a bank may pave the way to allow the development of appropriate tools towards the analysis of ancient Greek. The project is aimed to integrate the available digital resources, implementing and enriching what already exists and to develop crucial resources, materials and tools for study and research. All in all, we aim to develop a new type of approach to the study of Classics, opening new horizons for the study of the discipline. The project is expected to have a crucial impact in the field.

Research infrastructures seem to be the perfect place to make the results obtained concrete and visible. This newly created resource will be integrated into the existing CLARIN repository and provided with appropriate metadata. Finally, we can make ours the wishes of Nava (2019). It would be useful that the set of CLARIN-IT services were enriched with an integrated, specialized online platform aimed to support Digital and Classical Phylogists to proof-read, encode and enrich classical texts. In this respect, it would be helpful for CLARIN-IT to promote the development of tools tailored to researchers with no computational skills to help them in performing linguistic and textual annotations (morpho-syntactic, semantic, etc.) in a user-friendly and intuitive way.

\section{References}

Bridget Almas and Monica Berti. 2013. Perseids Collaborative Platform for Annotating Text Re-Uses of Fragmentary Authors. In DH-Case 2013. Proceedings of the 1st International Workshop on Collaborative Annotations in a Shared Environment: metadata, vocabularies and techniques in the Digital Humanities, 1-4. ACM New York, NY, USA (doi 10.1145/2517978.2517986)

Monica Berti. 2019. Digital Classical Philology. Ancient Greek and Latin in the Digital Revolution. De Gruyter, Berlin-Boston (ISBN 9783110599572).

Carmen Brando, Francesca Frontini, and Jean-Gabriel Ganascia. 2016. REDEN: Named Entity Linking in Digital Literary Editions Using Linked Data Sets. Complex Systems Informatics and Modeling Quarterly, 0 (7), 60-80.

Monica Monachini and Francesca Frontini. 2016. CLARIN, l'infrastruttura Europea Delle Risorse Linguistiche per Le Scienze Umane e Sociali e Il Suo Network Italiano CLARIN-IT. IJCoL - Italian Journal of Computational Linguistics, Special Issue on NLP and Digital Humanities, 2 (2), 11-30.

Monica Monachini, Anas Fahad Khan, Francesca Frontini and Anika Nicolosi. 2018. Linked Open Data and the Enrichment of Digital Editions: The Contribution of CLARIN to the Digital Classics. In Proceedings of the CLARIN Annual Conference 2018, edited by Inguna Skadina and Maria Eskevich, 159-162. Pisa, Italy. https://office.clarin.eu/v/CE-2018-1292-CLARIN2018_ConferenceProceedings.pdf.

Monica Monachini, Anika Nicolosi et al. 2018. Digital Classics and CLARIN-IT: What Italian Scholars of Ancient Greek Expect from Digital Resources and Technology. In Selected Papers from the CLARIN Annual Conference 
2017, Budapest, 18-20 September 2017, edited by M. Piasecki, 61-74. Linköping University Electronic Press, Linköpings universitet.

Beatrice Nava. 2019. Tour de CLARIN: Interview with, https://www.clarin.eu/blog/tour-de-clarin-interview-be$\underline{\text { atrice-nava }}$

Anika Nicolosi. 2013. Archiloco: elegie. Pàtron Editore, Bologna, Italy (ISBN 9788855532365). Google-BooksID: 9uj5oAEACAAJ.

Anika Nicolosi. 2015. Analisi testuale e linguistica di Lirici Arcaici e Adespoti Giambici ed Elegiaci: Ipotesi di ricerca di applicazione della Filologia Computazionale al Greco Antico. ILC-CNR, Pisa, Italy, November 6. http://www.ilc.cnr.it/sites/default/files/presentations/ILC-Thematic-Seminar_11.06.2015_Presentation.pdf

Anika Nicolosi. 2017. Archiloco. Testimonianze e frammenti. Aracne Editrice, Roma, Italy (ISBN 9788825508550).

Elena Pierazzo. 2014. Digital Scholarly Editing: Theories, Models and Methods. HAL Id: hal-01182162 